\title{
Clinical Experience Over 15 Years with the B-Lynch Compression Suture Technique in the Management of Postpartum Hemorrhage
}

\section{Experiência clínica ao longo de 15 anos com a técnica de sutura compressiva de B-Lynch no manejo da hemorragia pós-parto}

\author{
Gilberto Nagahama110 Henri Augusto Korkes ${ }^{20}$ \\ ${ }^{1}$ Department of Obstetrics, Hospital Maternidade Escola de Vila Nova \\ Cachoeirinha, São Paulo, SP, Brazil \\ 2 Department of Obstetrics and Gynecology, Faculty of Medicine, \\ Pontifícia Universidade Católica de São Paulo, São Paulo, SP, Brazil \\ 3 Department of Obstetrics, Escola Paulista de Medicina, Universidade \\ Federal de São Paulo, São Paulo, SP, Brazil
}

Nelson Sass ${ }^{30}$

Address for correspondence Gilberto Nagahama, MSc, Rua Dona Gabriela, 238, 02244-060, São Paulo, SP, Brazil (e-mail: gibanagahama@hotmail.com).

Rev Bras Ginecol Obstet 2021;43(9):655-661.

\begin{abstract}
Keywords

- postpartum hemorrhage

- uterine atony

- suture techniques

- maternal mortality

- surgical hemostasis

Objective To describe the clinical experience with the B-Lynch technique in the management of postpartum hemorrhage as well as the factors related to the indication of the technique and to present the success rates of the application of the B-Lynch technique.

Methods Observational, retrospective, cross-sectional, and analytical study. Patient data was obtained through the study of medical records. The study population comprised of patients who underwent hemostatic suture using the B-Lynch technique, including 104 patients within the period from January 1, 2005, to December 31, 2019. Results Of the total of 104 patients, $82.7 \%$ did not present any complications. Blood transfusion and intensive care unit admission were the most prevalent complications, with $13.5 \%$ and $15.4 \%$, respectively. Only $1 \%$ of the patients had puerperal and surgical site infections. The factors most related to the application of the technique were the presence of previous cesarean section (30.8\%), use of oxytocin (16.3\%), and preeclampsia (11.6\%). Puerperal hysterectomy was performed in $4.8 \%$ of the patients due to failure of the method.

Conclusion The clinical experience with the B-Lynch technique was satisfactory since it presented few complications, with excellent results in hemorrhagic control. Previous cesarean section, the use of oxytocin, and preeclampsia stood out as factors related to the indication of the application of the technique, and the success rate in controlling postpartum hemorrhage was $95.2 \%$.
\end{abstract}

received

August 25, 2020

accepted

July 22, 2021
DOI https://doi.org/

10.1055/s-0041-1735228. ISSN 0100-7203. (c) 2021. Federação Brasileira de Ginecologia e Obstetrícia. All rights reserved.

This is an open access article published by Thieme under the terms of the Creative Commons Attribution License, permitting unrestricted use, distribution, and reproduction so long as the original work is properly cited. (https://creativecommons.org/licenses/by/4.0/)

Thieme Revinter Publicações Ltda., Rua do Matoso 170, Rio de Janeiro, RJ, CEP 20270-135, Brazil 


\section{Resumo}

\section{Palavras-chave}

- hemorragia pós-parto

- atonia uterina

- técnicas de sutura

- mortalidade materna

- hemostasia cirúrgica
Objetivo Descrever a experiência clínica com a técnica de B-Lynch no manejo da hemorragia pós-parto e os fatores relacionados à indicação da técnica bem como apresentar as taxas de sucesso da aplicação da técnica de B-lynch.

Métodos Estudo observacional, retrospectivo, de corte transversal e analítico. Os dados foram obtidos por estudo de prontuário. A população do estudo foi constituída de pacientes submetidas à sutura hemostática com a técnica de B-Lynch, sendo incluídas 104 pacientes dentro do período de 01 de janeiro de 2005 a 31 de dezembro de 2019.

Resultados Do total de 104 pacientes, 82,7\% não apresentaram qualquer complicação. A transfusão de sangue e a internação na UTI foram as complicações mais prevalentes, com $13,5 \%$ e $15,4 \%$, respectivamente. Apenas $1 \%$ teve infecção puerperal e do sítio cirúrgico. Os fatores mais relacionados com a aplicação da técnica foram a presença de cesárea anterior (30,8\%), uso de ocitocina $(16,3 \%)$ e pré-eclâmpsia $(11,6 \%)$. A histerectomia puerperal foi realizada em $4,8 \%$ das pacientes por falha do método.

Conclusão A experiência clínica com a técnica de B-Lynch foi satisfatória, pois apresentou poucas complicações, com excelentes resultados no controle hemorrágico. A cesárea anterior, o uso de ocitocina e a pré-eclâmpsia se destacaram como fatores relacionados à indicação da aplicação da técnica. A taxa de sucesso avaliada foi de $95,2 \%$.

\section{Introduction}

Maternal mortality (MM) is a tragic event of worldwide proportions. Worldwide, it is estimated that 300,000 maternal deaths occur every year according to the World Health Organization (WHO), 94\% of which occur in poor or developing countries. Note that the majority could have been avoided. ${ }^{1}$

Maternal mortality has been declining globally, with significant differences among several countries. Effective compliance with strategies for its reduction provided a greater understanding of the social causes of MM, such as the role of education, income distribution, and place of birth.,3

In Brazil, according to the $\mathrm{WHO}$, the national MM ratio (MMR) was 60 deaths in 2017. Compared to the year 1990, which had a MMR of 104 deaths, a significant reduction of $42.3 \%$ occurred in this period. However, when we analyze countries such as Japan and the United States of America, which presented, respectively, MMRs of 5 and 19 deaths in the same period, it is clear how much progress needs to be made so that women's health can reach acceptable coefficients in our country. ${ }^{2}$

Postpartum hemorrhage (PPH) is responsible for 25 to $30 \%$ of MM worldwide. In Brazil, 13.3\% of MM is due to antepartum and PPH. It is the second most important direct obstetric cause, and, unfortunately, it remains one of the most important causes of preventable MM. ${ }^{1,4}$

Uterine atony (UA) is the most common cause of PPH, and it is responsible for $\sim 80 \%$ of all cases of this concerning pathology. ${ }^{5}$ The traditional treatment of UA is established by a sequence of actions well defined by global protocols. In the case of therapeutic failure with the initial clinical pharmacological measures, other methods must be promptly ap- plied to control uterine hemorrhage. Surgical methods such as selective arterial embolization, internal iliac or uterine artery ligation, and total or subtotal hysterectomy are presented as effective treatment options. ${ }^{6,7}$ However, they show an excessively invasive nature, requiring longer execution time, and a long learning curve; consequently, they are associated with more comorbidities, such as greater volume of hemorrhage and risk of injury to adjacent structures, such as the ureter, intestines, and bladder. ${ }^{7}$

The search for less invasive techniques easily reproducible and aiming at the possible preservation of fertility to avoid hysterectomies has brought about the so-called hemostatic suture techniques for the correction of atony conditions refractory to the initial measures. ${ }^{8-14}$

Hemostatic sutures have been part of the therapy to control PPH for at least two decades. Several techniques have emerged over the years with the same purpose of controlling PPH after non-surgical therapeutic failure and preserving the patient from more complex surgeries with greater comorbidities, such as hysterectomy. ${ }^{7-9}$

In Oxford, Christopher B-Lynch described a hemostatic compression suture technique, in 1997, in five cases of PPH secondary to UA which did not respond to the initial clinical-pharmacological treatment, thus introducing a new conservative alternative to surgeries with greater morbidity. ${ }^{8}$ The application of the technique has been recommended worldwide, being included in the routine clinical practice for PPH in several protocols around the world. A systematic review showed $91.7 \%$ of success rate in controlling $\mathrm{PPH}^{9,10,14,15}$

It is important to document this experience in a clinical study aimed at analyzing the clinical experience with the B-Lynch 
compression suture technique in the management of PPH at the Hospital Maternidade Escola Vila Nova Cachoeirinha (HMEVNC) over 15 years, in addition to identifying the factors related to the indication for use of the technique. The success rates of the BLynch compression suture technique in controlling PPH were also analyzed.

\section{Methods}

This is an observational, retrospective, cross-sectional, and analytical study. The study population consisted of patients who underwent uterine compression suture using the B-Lynch technique at HMEVNC within the period from January 1, 2005, to December 31, 2019. The number of patients included was defined by a convenience sample of 104 patients.

Regarding the use of the method, we state that the BLynch hemostatic suture was included in the clinical practice protocol of the HMEVNC as of 2005. This pioneering experience in Brazil was recorded in a national publication reporting a series of four cases of successfully controled PPH using the B-Lynch suture technique. ${ }^{16}$ Since then, this experience was expanded to be incorporated into their routine clinical practices.

In our center, the indication for applying the B-lynch suture was exclusively due to UA related to several risk factors and management of UA is established by a sequence of actions. These actions initiated immediately after the diagnosis of PPH due to UA initially include bimanual uterine compression, described as the Hamilton maneuver concomitant with the use of uterotonics, with intravenous oxytocin being the first option. The ergot alkaloids should be applied if the initial therapy with oxytocin fails, observing the contraindication for hypertensive patients. Misoprostol, an analogue of type E1 prostaglandin, is the third drug in the therapeutic sequence. Intrauterine balloon tamponade is not available at our center. Therefore, if after pharmacological treatment fails to control $\mathrm{PPH}$, we immediately apply the B-lynch suture, regardless of the parity or severity of uterine bleeding.

The document analysis to obtain the patient's data was performed on the study of medical records. These records were selected from a notebook available at the obstetric center for exclusive use to write down the full names and medical record of the patients who underwent the B-Lynch suture technique. Data was collected exclusively by the main researcher using a spreadsheet created with the software Microsoft Excel, version for Office 365 (Microsoft Corp., Redmond, WA, USA).

The selected analysis variables were grouped and defined as follows:

Pregnancy and childbirth variables:

1. Gestational age: defined in complete weeks at the time of delivery, counting by the date of the last menstrual period (LMP), if reliable, or by ultrasound, if LMP $w$ unknown or unreliable.

2. Number of pregnancies: considered the sum of current and previous pregnancies, regardless of gestational age, vitality, or location.
3. Parity: defined as the number of deliveries whose newborn weighed $\geq 500 \mathrm{~g}$ or reached gestational age $\geq 20$ weeks, regardless of the number of fetuses or outcomes.

4. Antenatal care: considered performed only for patients who attended six or more appointments. ${ }^{17}$

5. Use of oxytocin to induce or conduct labor;

6. Previous cesarean section: 1 or more;

7. Preeclampsia: manifestation of hypertension after the 20th week of pregnancy associated with significant proteinuria or associated with systemic impairment or damage to the target organs (thrombocytopenia, liver dysfunction, renal failure, pulmonary edema, impending eclampsia, or eclampsia) ${ }^{18}$;

8. Polyhydramnios: defined as an increase in the amount of amniotic fluid $^{19}$;

9. Placental abruption: defined as the premature separation of the normal-sited placenta from the uterus ${ }^{20}$;

10. Fetal macrosomia: defined as birthweight greater than $4,000 \mathrm{~g}^{21}$;

11. Grand multiparity: defined as five deliveries or more ${ }^{22}$;

\section{Postpartum variables}

1. Blood transfusion: the process of transferring blood components, such as red blood cells, plasma, clotting factors, and platelets was based on hemodynamic instability with hemoglobin lower than $7 \mathrm{~g} / \mathrm{dL}$ or coagulopathy.

2. Postpartum infection: defined as reproductive tract infection occurring after delivery. ${ }^{23}$

3. Complications of the surgical wound: defined as an abnormality in the evolution of healing, such as dehiscence and surgical site infection.

4. Failure of the method: defined as the need for puerperal hysterectomy after application of the B-Lynch technique.

5. Puerperal hysterectomy: defined as a surgical procedure for removing the uterus by laparotomy when hemodynamic instability persists after failure of conservative hemostatic methods. ${ }^{7}$

It is important to note that the data collected from the postpartum variables was restricted only to the patients' hospitalization period, considered a short period of observation.

The data was analyzed using descriptive methods to characterize the variables collected during the study. Categorical variables were analyzed using absolute and relative frequencies. Continuous variables were analyzed using medians. For qualitative variables, the ratios were also estimated with their respective $95 \%$ confidence intervals. The data was analyzed using the software R, v. 3.4.1.

The present study was approved by the ethics in research committee of the Universidade Federal de São Paulo and HEMVNC, with due authorization to waive the informed consent form of all patients.

\section{Results}

Regarding the obstetric conditions at hospitalization, - Table 1 illustrates the mean gestational age-which was 38 weekswhile the mean number of pregnancies and deliveries was 2.4 
Table 1 Obstetric conditions at hospitalization of patients who underwent the B-Lynch technique

\begin{tabular}{|c|c|c|c|c|c|c|c|}
\hline Condition & $\mathrm{n}$ & $\%$ & Average & $95 \% \mathrm{Cl}$ & Median & Minimum value & Maximum value \\
\hline Gestational age & & & 38.0 & $37.4-38.6$ & 39.0 & 22.0 & 41.0 \\
\hline$\geq 37$ & 86 & $82.7 \%$ & & & & & \\
\hline $34-36$ & 11 & $10.6 \%$ & & & & & \\
\hline$\leq 33$ & 7 & $6.7 \%$ & & & & & \\
\hline TOTAL & 104 & $100.0 \%$ & & & & & \\
\hline Number of pregnancies* & & & 2.4 & $2.0-2.7$ & 2 & 1 & 9 \\
\hline 1 & 44 & $42.3 \%$ & & & & & \\
\hline $2-4$ & 48 & $46.2 \%$ & & & & & \\
\hline$\geq 5$ & 12 & $11.5 \%$ & & & & & \\
\hline TOTAL & 104 & $100.0 \%$ & & & & & \\
\hline Parity** & & & 1.01 & $0.80-1.4$ & 1 & zero & 6 \\
\hline Nulliparous & 50 & $48.1 \%$ & & & & & \\
\hline $1-2$ & 40 & $38.4 \%$ & & & & & \\
\hline $3-4$ & 9 & $8.7 \%$ & & & & & \\
\hline$\geq 5$ & 5 & $4.8 \%$ & & & & & \\
\hline TOTAL & 104 & $100.0 \%$ & & & & & \\
\hline Previous cesarean section $(n=104)$ & 32 & $30.8 \%$ & & & & & \\
\hline Antenatal care ( $\geq 6$ visits) $(n=104)$ & 93 & $89.4 \%$ & & & & & \\
\hline
\end{tabular}

*Number of pregnancies: considered the sum of current and previous pregnancies, regardless of gestational age, vitality, or location.

** Parity: defined as the number of previous deliveries whose newborn weighed $\geq 500 \mathrm{~g}$ or reached gestational age $\geq 20$ weeks, regardless of the number of fetuses or outcomes.

and 1.01 , respectively. The median was 39 weeks regarding the gestational age, with the highest age being 41 weeks, and the lowest being 22 . Among the patients, $48.1 \%$ were nulliparous, and $30.8 \%$ of pregnant women had already had at least one previous cesarean section. At least 6 antenatal care visits were performed by $89.4 \%$ of patients.

The perinatal characteristics of the patients are shown in - Table 2, with $96.2 \%$ having a cesarean delivery, with $93.3 \%$ of these having cephalic presentation. Regarding birth weight, $13 \%$ were underweight, and $9.2 \%$ were macrosomal. - Table 2 also shows that 100\% of patients received oxytocin and misoprostol in the pharmacological treatment for atony, and $86.5 \%$ also used ergometrine.

- Table 3 shows the percentage of patients who presented some risk factor for UA.

The frequency of complications after the surgery is analyzed and shown in - Table 4, and 77.9\% had no complications related to B-Lynch suture or PPH. Regarding hospitalization, most patients remained hospitalized for up to 3 days, and $15.4 \%$ required intensive care unit (ICU) care. The same table also shows that the frequency of puerperal infection was $1 \%$, and there were five hysterectomies due to failure of hemostasis with the use of the B-Lynch technique representing $4.8 \%$ of patients.

\section{Discussion}

The B-Lynch hemostatic suture was included in the clinical practice protocol of the HMEVNC in 2005. Since then, the clinical experience at this Maternity Hospital School has only improved. $^{16}$

A limitation of the present study should be noted. The patients were observed in a short period, which makes it impossible to assess late complications. A total of 104 patients were divided into groups of pregnancy-puerperium cycle variables. Regarding gestational age, we had $82.7 \%$ of full-term births, and $17.3 \%$ of prematurity, with $61.2 \%$ of these being late preterm babies. Prematurity is often associated with indications intended to safeguard the mother-fetus binomial. ${ }^{24}$ The premature interruption of high-risk pregnancies often has the cesarean section as the mode of delivery, and this association implies a greater hemorrhagic risk. The lower uterine segment becomes thicker, and has a larger surface area of the myometrium, which would lead to greater blood loss. ${ }^{25}$

Among the patients, $48.1 \%$ were nulliparous, and only $5.8 \%$ were considered grand multiparous women. There is a direct relation between socioeconomic conditions and parity, as this condition is implicit in the access to information, as well as in the various methods for adequate family planning. Grand multiparity is an additional risk factor for worse mother-fetus outcomes, regardless of other factors. ${ }^{22}$

At least $30.8 \%$ of pregnant women in our study had previously had a cesarean section. In 2016, we had 55\% of cesarean deliveries in Brazil, whereas the rate was $40 \%$ in Brazil's unified health system (SUS), which is still far from the WHO recommendations. The main objective of the cesarean 
Table 2 Perinatal characteristics of patients who underwent the B-Lynch technique

\begin{tabular}{|c|c|c|}
\hline Condition & $\mathbf{n}$ & $\%$ \\
\hline \multicolumn{3}{|l|}{ Type of delivery } \\
\hline Cesarean section & 100 & 96.2 \\
\hline Vaginal & 4 & 3.8 \\
\hline TOTAL & 104 & 100.0 \\
\hline \multicolumn{3}{|l|}{ Presentation } \\
\hline Cephalic & 97 & 93.3 \\
\hline Pelvic & 7 & 6.7 \\
\hline TOTAL & 104 & 100.0 \\
\hline \multicolumn{3}{|l|}{ Birth weight (g) } \\
\hline$<2,500$ & 14 & 13.0 \\
\hline $2,500-3,999$ & 84 & 77.8 \\
\hline$\geq 4,000$ & 10 & 9.2 \\
\hline TOTAL & 108 & 100.0 \\
\hline \multicolumn{3}{|c|}{ Use of oxytocin to treat PPH } \\
\hline Yes & 104 & 100.0 \\
\hline No & 0 & 0.00 \\
\hline TOTAL & 104 & 100.0 \\
\hline \multicolumn{3}{|c|}{ Use of ergomethrin } \\
\hline Yes & 90 & 86.5 \\
\hline No & 14 & 13.5 \\
\hline TOTAL & 104 & 100.0 \\
\hline \multicolumn{3}{|l|}{ Use of misoprostol } \\
\hline Yes & 104 & 100 \\
\hline No & 0 & 0.00 \\
\hline TOTAL & 104 & 100 \\
\hline \multicolumn{3}{|c|}{ Days of postpartum hospitalization } \\
\hline$\leq 3$ & 88 & 84.6 \\
\hline $4-7$ & 15 & 14.4 \\
\hline$\geq 8$ & 1 & 1.0 \\
\hline TOTAL & 104 & 100.0 \\
\hline
\end{tabular}

section is to safeguard the mother-fetus well-being in risk situation for this binomial. However, it is currently an iatrogenic epidemic in our country, with this important surgery included in the category of risk factor, among which we include the puerperal hemorrhages. ${ }^{26}$

Regarding antenatal care, 89.4\% had at least 6 visits. According to the Ministry of Health of Brazil, this number of appointments in a well-qualified manner and with professional training could be sufficient to identify risks and take preventive actions, or even to refer the patient to more complex services, thereby reducing the mother-fetus morbidity and mortality. ${ }^{27}$

Concerning the clinical and obstetric conditions of patients at the time of admission, we found $36.5 \%$ of them had no risk factor for UA. Many cases do not present any identifiable risk factor in the antepartum nor in the intra-
Table 3 Risk factors for uterine atony identified in patients who underwent the B-Lynch technique

\begin{tabular}{lll}
\hline Risk factor & $\mathbf{n}$ & $\%$ \\
\hline NONE $(n=104)$ & 38 & 36.5 \\
Previous cesarean section $(n=104)$ & 32 & 30.8 \\
Use of oxytocin for & 17 & 16.3 \\
induction/conduction of labor & & \\
$(n=104)$ & 12 & 11.6 \\
Preeclampsia $(n=104)$ & 9 & 8.7 \\
Fetal macrosomia $(n=104)$ & 9 & 8.7 \\
Placental abruption $(n=104)$ & 4 & 3.8 \\
Twinning ( $n=104)$ & 5 & 4.8 \\
Grand multiparity $(n=104)$ & 2 & 1.9 \\
Polyhydramnios $(n=104)$ &
\end{tabular}

Table 4 Puerperal complications in patients who underwent the B-Lynch technique

\begin{tabular}{lll}
\hline Complications & $\mathbf{n}$ & $\%$ \\
\hline One or more complications $(n=104)$ & 23 & 22.1 \\
Blood transfusion $(n=104)$ & 14 & 13.5 \\
ICU admission $(n=104)$ & 16 & 15.4 \\
Puerperal infection $(n=104)$ & 1 & 1.0 \\
Surgical site infection $(n=104)$ & 1 & 1.0 \\
Puerperal hysterectomy $(n=104)$ & 5 & 4.8 \\
\hline
\end{tabular}

partum, which justifies a careful observation of the risk signs of hemodynamic instability so that the hemorrhagic control actions can be performed immediately. ${ }^{28}$

In relation to the perinatal characteristics of the patients studied, $96.2 \%$ had a cesarean delivery with precise obstetric indications, and this type of operative delivery represents an increased hemorrhagic risk. ${ }^{26,29}$

Still regarding the perinatal characteristics, we show that $100 \%$ of the patients received oxytocin and misoprostol in the pharmacological treatment for atony, and $86.5 \%$ also used ergometrine, showing that all patients received the appropriate pharmacological treatment to correct UA, and that $13.5 \%$ did not receive ergometrine because they had chronic hypertension or preeclampsia, which contraindicates the use of ergotamine derivatives. ${ }^{7}$

Among the various risk factors for $\mathrm{PPH}$, previous cesarean section stood out in the present study, representing $30.8 \%$ of patients, followed by the use of oxytocin, which corresponded to $16.3 \%$, and $11.6 \%$ were diagnosed with preeclampsia. The alarming rates of cesarean sections are going up worldwide, and the increase in hemorrhagic risk is well established both in patients with a previous cesarean section who underwent a new cesarean section and in patients who are undergoing cesarean delivery for the first time. $^{26}$ The use of oxytocin may pose greater risks for the development of UA. In 2010, Balki et al. demonstrated that 
there would be a desensitization of specific uterine oxytocin receptors for patients who were exposed to high doses of oxytocin for a long period, which would justify its refractoriness in previously exposed patients. ${ }^{30}$

I emphasize that $15.4 \%$ needed ICU hospitalization, and $13.5 \%$ were transfused with blood products. It would be reasonable to assume that even though the percentage of patients in the ICU and transfused is high, it could have been even higher if the patients had not undergone the B-Lynch technique. It is still valid to state that the obstetric emergency related to hemorrhage itself poses a risk for transfusion. It is noteworthy that the uterine blood flow is $\sim 600 \mathrm{ml} /$ minute in a term pregnancy, which can lead to a very considerable blood loss in a short period. ${ }^{31}$

The frequency of puerperal infection and surgical wound was only $1 \%$. Puerperal hysterectomy is considered a failure of the method, and it occurred in $4.8 \%$ of patients, showing that the vast majority was preserved from a procedure with greater comorbidity in addition to having their uterus preserved. In addition to the B-Lynch technique being simple and of lower risk for comorbidities, the preservation of the uterus as a way of preserving fertility had a great impact on patients and family members. It is noteworthy that, in this study, $95.2 \%$ of the patients had their uterus preserved, escaping the possibility of having a more aggressive procedure and with a greater comorbidity such as hysterectomy.

However, it should be noted that individual training to perform the B-Lynch technique and the preparation of multiprofessional teams for immediate intervention in the control of PPH are mandatory for the results to be satisfactory.

Although our results were very satisfactory to recommend its practice, we understand that there is room for assessing the possible long-term impacts, and that they were not included in the objectives of the present study.

More studies are necessary in our country to clarify the role of B-Lynch in the women's reproductive health including fertility, chronic pelvic pain, dyspareunia, and menstruation.

\section{Conclusion}

The clinical experience with the B-Lynch technique was satisfactory since it presented few complications, with excellent results in hemorrhagic control. Previous cesarean section, the use of oxytocin and preeclampsia stood out as factors related to the indication of the application of the technique, and the success rate in controlling PPH was 95.2\%.

\section{Contributions}

Data collection was performed by Nagahama G., and all the authors contributed to conception, design, analysis, and interpretation, article essay, and final approval of the text version to be published.

\section{Conflict of Interests}

The authors have no conflict of interests to declare.

\section{Acknowledgments}

The authors would like to acknowledge the Coordination for the Improvement of Higher Education Personnel
(CAPES, in the Portuguese acronym) for the financial support. (Process number: 1726483) This funding agency had no role in the design and conduct of the study.

\section{References}

1 Alkema L, Chou D, Hogan D, et al; United Nations Maternal Mortality Estimation Inter-Agency Group collaborators and technical advisory group. Global, regional, and national levels and trends in maternal mortality between 1990 and 2015, with scenario-based projections to 2030: a systematic analysis by the UN Maternal Mortality Estimation Inter-Agency Group. Lancet. 2016;387 (10017):462-474. Doi: 10.1016/S0140-6736(15)00838-7

2 Trends in maternal mortality: 2000 to 2017: estimates by WHO, UNICEF, UNFPA, World Bank Group, United Nations Population Division. Geneva: WHO; 2019

3 Thomas TN, Gausman J, Lattof SR, Wegner MN, Kearns AD, Langer A. Improved maternal health since the ICPD: 20 years of progress. Contraception. 2014;90(6, Suppl):S32-S38. Doi: 10.1016/j.contraception.2014.06.026

4 Ministério da Saúde. DATASUS. Informações de Saúde (TABNET) [Internet]. Brasília, DFMinistério da Saúde2020 [cited 202015 Jun]. Available from: http://www2.datasus.gov.br/DATASUS/index.php?area $=02$

5 Haeri S, Dildy GA III. Maternal mortality from hemorrhage. Semin Perinatol. 2012;36(01):48-55. Doi: 10.1053/j.semperi.2011.09.010

6 Selçuk İ, Uzuner B, Boduç E, Baykuş Y, Akar B, Güngör T. Step-by-step ligation of the internal iliac artery. J Turk Ger Gynecol Assoc. 2019; 20(02):123-128. Doi: 10.4274/jtgga.galenos.2018.2018.0124

7 Committee on Practice Bulletins-Obstetrics. Practice Bulletin No. 183: postpartum hemorrhage. Obstet Gynecol. 2017;130(04): e168-e186. Doi: 10.1097/AOG.0000000000002351

8 B-Lynch C, Coker A, Lawal AH, Abu J, Cowen MJ. The B-Lynch surgical technique for the control of massive postpartum haemorrhage: an alternative to hysterectomy? Five cases reported. $\mathrm{Br}$ J Obstet Gynaecol. 1997;104(03):372-375. Doi: 10.1111/j.14710528.1997.tb11471.x

9 El-Hamamy E, B-Lynch C. A worldwide review of the uses of the uterine compression suture techniques as alternative to hysterectomy in the management of severe post-partum haemorrhage. J Obstet Gynaecol. 2005;25(02):143-149. Doi: 10.1080/01443610500040752

10 El-Hamamy E, Wright A, B-Lynch C. The B-Lynch suture technique for postpartum haemorrhage: a decade of experience and outcome. J Obstet Gynaecol. 2009;29(04):278-283. Doi: 10.1080/01443610902 797645

11 Cho JH, Jun HS, Lee CN. Hemostatic suturing technique for uterine bleeding during cesarean delivery. Obstet Gynecol. 2000;96(01): 129-131. Doi: 10.1016/s0029-7844(00)00852-8

12 Schnarwyler B, Passweg D, von Castelberg B. [Successful treatment of drug refractory uterine atony by fundus compression sutures]. Geburtshilfe Frauenheilkd. 1996;56(03):151-153. Doi: 10.1055/s-2007-1022282 German.

13 Hayman RG, Arulkumaran S, Steer PJ. Uterine compression sutures: surgical management of postpartum hemorrhage. Obstet Gynecol. 2002;99(03):502-506. Doi: 10.1016/s0029-7844(01) 01643-x

14 Mallappa Saroja CS, Nankani A, El-Hamamy E. Uterine compression sutures, an update: review of efficacy, safety and complications of B-Lynch suture and other uterine compression techniques for postpartum haemorrhage. Arch Gynecol Obstet. 2010;281 (04):581-588. Doi: 10.1007/s00404-009-1249-z

15 Doumouchtsis SK, Papageorghiou AT, Arulkumaran S. Systematic review of conservative management of postpartum hemorrhage: what to do when medical treatment fails. Obstet Gynecol Surv. 2007;62(08):540-547. Doi: 10.1097/01.ogx.0000271137.81361.93

16 Nagahama G, Vieira LC, Jover PB, et al. [The control of postpartum hemorrhage with the B-Lynch suture technique: a case series]. 
Rev Bras Ginecol Obstet. 2007;29(03):120-125. Doi: 10.1590/ S0100-72032007000300002 Portuguese.

17 Ministério da Saúde. Secretaria de Atenção à Saúde. Departamento de Atenção Básica. Atenção ao pré-natal de baixo risco Brasília, DF: Editora do Ministério da Saúde; 2013

18 American College of Obstetricians and Gynecologists Task Force on Hypertension in Pregnancy. Hypertension in pregnancy. Report of the American College of Obstetricians and Gynecologists' Task Force on Hypertension in Pregnancy. Obstet Gynecol. 2013;122(05): 1122-1131. Doi: 10.1097/01.AOG.0000437382.03963.88

19 Owen J, Albert PS, Buck Louis GM, et al. A contemporary amniotic fluid volume chart for the United States: The NICHD Fetal Growth Studies-Singletons. Am J Obstet Gynecol. 2019;221(01):67.e1-67. e12. Doi: 10.1016/j.ajog.2019.02.030

20 Downes KL, Grantz KL, Shenassa ED. Maternal, labor, delivery, and perinatal outcomes associated with placental abruption: a systematic review. Am J Perinatol. 2017;34(10):935-957. Doi: 10.1055/s-0037-1599149

21 Macrosomia: ACOG Practice Bulletin Summary, Number 216. Obstet Gynecol. 2020;135(01):246-248. Doi: 10.1097/ AOG.0000000000003607

22 Mgaya AH, Massawe SN, Kidanto HL, Mgaya HN. Grand multiparity: is it still a risk in pregnancy? BMC Pregnancy Childbirth. 2013;13:241. Doi: 10.1186/1471-2393-13-241

23 Song H, Hu K, Du X, Zhang J, Zhao S. Risk factors, changes in serum inflammatory factors, and clinical prevention and control measures for puerperal infection. J Clin Lab Anal. 2020;34(03):e23047. Doi: $10.1002 /$ jcla.23047
24 Leal MD, Esteves-Pereira AP, Nakamura-Pereira M, et al. Prevalence and risk factors related to preterm birth in Brazil. Reprod Health. 2016;13(Suppl 3):127. Doi: 10.1186/s12978-016-0230-0

25 Kino T, Yamamoto Y, Saigusa Y, Aoki S, Miyagi E. Adverse pregnancy outcomes related to preterm cesarean delivery. Eur J Obstet Gynecol Reprod Biol. 2019;234:89-91. Doi: 10.1016/j.ejogrb.2018.12.033

26 Korb D, Goffinet F, Seco A, Chevret S, Deneux-Tharaux CEPIMOMS Study Group. Risk of severe maternal morbidity associated with cesarean delivery and the role of maternal age: a populationbased propensity score analysis. CMAJ. 2019;191(13):E352-E360. Doi: 10.1503/cmaj.181067

27 Calderon IM, Cecatti JG, Vega CE. [Beneficial interventions for maternal mortality prevention in the prenatal period]. Rev Bras Ginecol Obstet. 2006;28(05):310-315. Doi: 10.1590/S010072032006000500008 Portuguese

28 World Health Organization. Recommendations for the prevention and treatment of postpartum haemorrhage. Geneva: WHO; 2017

29 World Health Organization Human Reproduction Programme. WHO statement on caesarean section rates. Geneva: WHO; 2015

30 Balki M, Cristian AL, Kingdom J, Carvalho JC. Oxytocin pretreatment of pregnant rat myometrium reduces the efficacy of oxytocin but not of ergonovine maleate or prostaglandin F $2 \alpha$. Reprod Sci. 2010;17(03):269-277. Doi: 10.1177/1933719109351934

31 Rigano S, Ferrazzi E, Boito S, Pennati G, Padoan A, Galan H. Blood flow volume of uterine arteries in human pregnancies determined using 3D and bi-dimensional imaging, angio-Doppler, and fluid-dynamic modeling. Placenta. 2010;31(01):37-43. Doi: 10.1016/j.placenta.2009.10.010 